\section{Radiocarbon chronology of Andean khipus}

\author{
Alexander Cherkinsky, ${ }^{1}$ Gary Urton ${ }^{2}$ \\ ${ }^{1}$ Center for Applied Isotope Studies, \\ University of Georgia, Athens, GA; \\ 2Department of Anthropology, Harvard \\ University, Cambridge, MA, USA
}

\section{Abstract}

Unlike every other high civilisation of the ancient world, the Incas did not develop a system of writing based on graphic signs on twodimensional surfaces. Rather, Inca administrative records took the form of three-dimensional knotted-cords made of spun and plied fibers. It is widely believed that khipu technology associated with the rise and expansion of the Inca Empire, during the Late Horizon period (ca. 1400-1532 AD), developed out of an earlier cord recording technology associated with the Wari culture of the Middle Horizon period (ca. 600-1000 AD). There were good studies of the patterns of thread-wrapping on a few Middle Horizon samples and archaeological recovery of one sample from Middle Horizon context. Three Middle Horizon, Wari khipus have been dated between 780-1024 AD. The principal problem of khipu chronology arises with respect to the dating of Inca samples. Thirty-one samples of Inca khipus from museums in the USA, Latin America and Germany have been analysed. The samples were analysed by the accelerator mass spectrometry technique at three laboratories. About half of the samples analysed at the University of Georgia have been analysed twice to get a higher precision. Most of the samples have been dated from Late Horizon times to the early Colonial period, 1500-1600 AD. One of the samples was dated to the beginning of the Late Horizon 1390-1423 AD and another sample was even earlier, i.e. 1188-1282 AD. Unfortunately, the existing calibration data for Inca khipus do not allow high enough sensitivity for precise analysis, thereby requiring a reappraisal of the calibration curve for South America.

\section{Introduction}

Unlike every other high civilisation of the ancient world (Old or New), the Incas did not develop a system of writing based on graphic signs painted, etched, or otherwise produced by marking on two-dimensional surfaces. Rather, Inca administrative records took the form of three-dimensional knotted-cords made of spun and plied cotton or camelid fibers. We know of Inca record keeping from two principal sources. First, some 850 samples survive in museum collections in South America, North America and Europe (Ascher, 1997; Urton, 2003). And second, the Spanish, who conquered the Incas over the course of the $16^{\text {th }}$ century, left extensive descriptions of these devices in their chronicles and documents (Urton, 2008). The latter include transcriptions of khipu readings performed by native record keepers - the khipukamayuqs (knot keepers/makers) - in testimony before Spanish scribes during the colonial period, primarily from the 1540 s through the end of the $16^{\text {th }}$ century (Pärssinen and Kiviharju, 2004). One of the central problems that khipu researchers confront today concerns chronology. That is, since the Incas did not write - at least not in a way we have succeeded in reading, or interpreting, their texts - we do not have first-hand accounts concerning when cord keeping began or of how the system might have evolved over the centuries leading up to the Spanish conquest, in 1532. We take up the question of chronology after a brief introduction to khipu cord construction.

\section{Inca Khipus: a brief introduction}

Khipus are made of strings composed of spun and plied threads of cotton or camelid (llama and alpaca) fibers. Basic khipu structures include a ca. $0.5 \mathrm{~cm}$ in diameter cord of variable length, referred to as a primary cord. A variable number of thinner strings, called pendant cords, are tied onto the primary cords. The number of pendant cords ranges from two to more than 1500 ; the average number of pendants on the some 480 khipus currently entered into the khipu database (KDB) at Harvard University is 60 (the median is 27). In addition to primary and pendant cords, secondary - so-called subsidiary - cords are attached to $35 \%$ of all pendant cords. A subsidiary may itself carry a subsidiary (tertiary) cord, and so on through multiple levels of subsidiary cords. One sample in Chile contains 6 levels of subsidiary cords. Therefore, primary, pendant and subsidiary cords form dense, hierarchicallyarrayed arrangements of cords.

Additional components of khipu data structures include knots which are tied on different levels, in tiered clusters, along pendant and subsidiary cords. The knots are the constituents of a system of recording values in a base-10 system, the tiers of the knot arrays representing the different decimal place values $(1,10,100 \mathrm{~s}$, etc.). Simple overhand (single) knots signify full decimal units; long knots - i.e. knots having from 2-9 turns of the cord inside the body of the knot - signify the values 2-9; and figure-eight knots signify ones. Single, long and figure-eight knots are tied in two different ways, resulting in diagonal axes running across or through the knots like the
Correspondence: Alexander Cherkinsky, Center for Applied Isotope Studies, University of Georgia, 120 Riverbend Road, 30602 Athens, GA, USA

Tel. +1.706.542.1395 - Fax: +1.706.542.6106.

E-mail: acherkin@uga.edu

Key words: khipu, radiocarbon dating, AMS, calibration.

Acknowledgements: this work was carried out as part of a methodological project on the dating of archaeological objects at the Center for Applied Isotope Studies of University of Georgia. We thank the Peabody Museum at Harvard University, the Carlos Museum, Emory University, the American Museum of Natural History, New York, the Museum für Völkerkunde, Berlin, Germany, the Museo Chileno de Arte Precolombino, Santiago, Chile, the Centro Mallqui, Leymebamba, Peru, and the Museo Temple-Radicati, Lima, Peru, for supplying the khipu samples for analysis.

Citation: Cherkinsky A, Urton G, 2014. Radiocarbon chronology of Andean khipus. In: RH Tykot (ed.), Proceedings of the $38^{\text {th }}$ International Symposium on Archaeometry - May $10^{\text {th }}-14^{\text {th }}$ 2010, Tampa, Florida. Open Journal of Archaeometry 2:5260.

Presented at the $38^{\text {th }}$ International Symposium on Archaeometry - May $10^{\text {th }}-14^{\text {th }} 2010$, Tampa, Florida.

This work is licensed under a Creative Commons Attribution 3.0 License (by-nc 3.0).

(C) Copyright A. Cherkinsky and G. Urton, 2014 Licensee PAGEPress, Italy

Open Journal of Archaeometry 2014; 2:5260 doi:10.4081/arc.2014.5260

diagonal axes of an $\mathrm{S}$ or a $\mathrm{Z}$; these knot variants are termed, respectively, S-knots and Zknots. In addition to hierarchically-arrayed cord and knot arrangements, data structures include colour variations. Khipu cords display great colour differences depending on the hue of the raw material - i.e. the cotton and/or camelid fibers - used in cord construction. Cords may also be dyed in a remarkable range of hues using vegetal dyes. Some 52 different colour hues have been recorded on khipus to date. Cords may be monotone, twisted twocolour in a barber pole style, or two- or threecolour mottled. In addition, colour may change between one to three times down the length of a single cord.

In sum, the khipu data structures are hierarchically arrayed arrangements of variablyhued primary, pendant, and subsidiary cords bearing arrays of S- and/or Z-tied single, long, and/or figure-eight knots. These data structures constituted the recording system of Inca administrators, who recorded information per- 
taining to resources of interest to the Inca state, including census figures, tribute accounts, as well as genealogical, calendrical and even historical data.

\section{The problem of chronology}

It is widely believed that khipu technology associated with the rise and expansion of the Inca empire, during the Late Horizon period (ca. 1400-1532 AD), developed out of an earlier cord recording technology associated with the Wari culture of the Middle Horizon period (600-1000 AD). Wari cord keeping appears to have been performed not by way of knots (as with the Incas) but by thread wrapping cords with colourful bands of fine, brightly dyed threads of camelid fiber. Although we have good studies of the patterns of thread-wrapping on a few Middle Horizon samples (Conklin, 1982; Pereyra, 1997), we do not yet have convincing arguments for how information was encoded by means of thread wrapping, nor for how, when, or where Middle Horizon thread-wrapped khipus evolved into Late Horizon Inca knotted-string khipus.

The central chronological questions that face researchers are the following: i) when did cord-keeping technology begin in the Andes?; ii) do the thread-wrapped, so-called Wari khipus, in fact, date to the Wari period (i.e. the Middle Horizon, 600-1000 AD)?; iii) when did the tradition of multiple-knot, decimal-based, Inca-style khipus begin? (i.e. was this tradition in fact associated with the Late Horizon, 1400$1532 \mathrm{AD}$ ?); iv) did Inca cord-keeping technology develop roughly contemporaneously across the length and breadth of the empire? (i.e. are there early and late versions of Inca khipus?); v) given that cord-keeping technologies carried over into the early colonial period, how well and accurately can radiocarbon dating help distinguish between pre-Hispanic and colonial khipus?

\section{Materials and Methods}

One of the authors (GU) has collected for the dating five samples from Laguna de los Condores, one from the Museo de Arte Prcolombino (MCHAP), and one from the Carlos Museum of Emory University, which have been dated by accelerator mass spectrometry (AMS) laboratory at the University of Arizona (AMS) facility.

Seven samples from the Peabody Museum at Harvard University, ten samples from the Museum für Völkerkunde, Berlin, and four samples from the Museo Temple-Radicati, Lima, Peru, have been dated at the AMS laboratory of the Center for Applied Isotope Studies, University of Georgia.

Four samples of what are claimed to be
Middle Horizon, Wari khipus from the American Museum of Natural History, New York have been dated at Beta Analytic Inc. One of the samples submitted to Beta Analytic was a duplicate sample collected from the same khipu (270948/9-41.2/7678) to date; we have dated by radiocarbon technique a total of 31 khipu samples (Table 1).

Pre-treatment of samples varied slightly among the different laboratories. At the University of Arizona (Damon et al., 1989) and Beta Analytic facilities, samples were treated with diluted $\mathrm{HCl}$, diluted $\mathrm{NaOH}$, and again with acid with rinsing between each treatment.

At the CAIS at the University of Georgia, depending upon the condition of the fibers, khipu threads went through the following sequence: after physical cleaning and shredding into small fibers, the sample is put into an extraction thimble and subjected to washing in a mix of benzene and acetone (50:50) followed by rinsing with acetone in a Soxhlet apparatus to remove any fat contamination. The residue is then treated with a series of acid/alkali/acid washes with $1 \mathrm{~N} \mathrm{HCl}$ and $0.1 \mathrm{~N} \mathrm{NaOH}$, rinsed thoroughly with deionised water between treatments, and dried at $60^{\circ} \mathrm{C}$. For accelerator mass spectrometry analysis, the cleaned samples were combusted at $900^{\circ} \mathrm{C}$ in evacuated/sealed ampoules in the presence of $\mathrm{CuO}$.

The resulting carbon dioxide was cryogenically purified from the other reaction products and catalytically converted to graphite using the method of Vogel et al. (1987). The graphite ${ }^{14} \mathrm{C} /{ }^{3} \mathrm{C}$ ratios were measured using the CAIS $0.5 \mathrm{MeV}$ accelerator mass spectrometer (Cherkinsky et al., 2010). The sample ratios were compared to the ratio measured from the International standard OXI (NBS SRM 4990).

The sample ${ }^{13} \mathrm{C} /{ }^{12} \mathrm{C}$ ratios were measured separately using a stable isotope ratio mass spectrometer and expressed as $\delta^{13} \mathrm{C}$ with respect to $\mathrm{PDB}$, with an error of less than $0.1 \%$.

The radiocarbon dates have been calculated in radiocarbon years before 1950 (years BP), using the ${ }^{14} \mathrm{C}$ half-life of 5568 years. The error is quoted as one standard deviation and reflects both statistical and experimental errors. Dates have been corrected for isotope fractionation. All conventional radiocarbon dates expressed in radiocarbon years were calibrated to calendar years using the latest version of the calibration datasets IntCal09 (Reimer et al., 2009). Unfortunately the calibration curve for the Southern Hemisphere is less precise than the curves for the Northern Hemisphere. The Northern hemisphere has been separated into 3 zones with slightly different calibration curves depending on the specific atmospheric circulation and as a result of different ${ }^{14} \mathrm{C}$ concentrations. For the southern Hemisphere, we have only one curve, and more than half the points on that curve were measured in South Africa and New Zealand, which certainly have different oceanatmospheric circulation regimes from South America.

\section{Results and Discussion}

In general, as can be seen from Table 1, 27 samples, or about $90 \%$ of all analysed khipus, are in the range of conventional age between 300 and 419 radiocarbon years BP. After calibration to calendar years, these samples date between 1446 and $1663 \mathrm{AD}$ with 2 sigma of probability. This is the widest possible interval. As a result, we are unable to determine
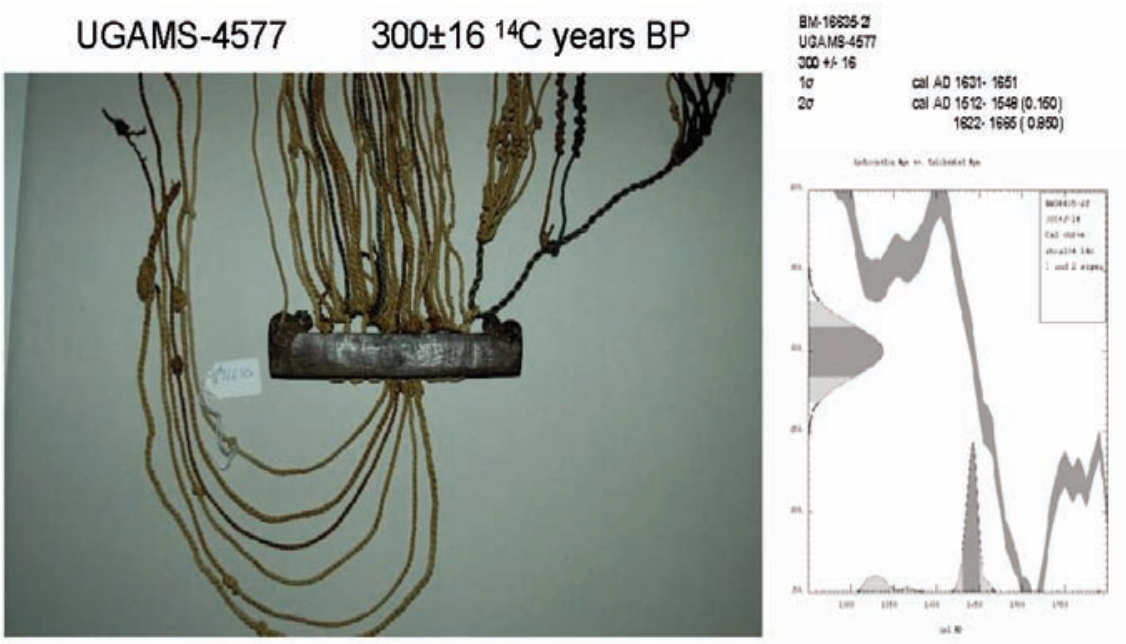

Figure 1. Colonial period khipu (khipu VA16635 on wooden bar from the Museum fur Völkerkunde) with two monkeys figures. The graph on the right shows the relative calibration results. 
absolutely whether these samples are Inca or Colonial khipus (the Spanish conquest began in $1532 \mathrm{AD}$ ). However, a more detailed analysis of the data allows nuances in readings to emerge. For example, VA16635, from the Museum für Völkerkunde, Berlin, a khipu mounted on a wooden bar with two monkey figures on either end, most likely was made in the middle of the $17^{\text {th }}$ century, between 1622 and 1663 years $\mathrm{AD}$ (Figure 1).

The majority of the samples dated at the University of Arizona AMS laboratory (prefixAA; Table 1) are from the large collection at the Chachapoya site of Laguna de los Cóndores, in northern Peru. With regard to the five radiocarbon dates from Laguna de los Cóndores, four of these AMS dates converted to calibrated ages that fall between $1479 \pm 38$ and
$1531 \pm 69$ AD. The typical example of decimal khipu is shown on Figure 2 with the calibrated range 1446-1616 $\mathrm{AD}$ for $2 \sigma$ of standard deviation. The fifth AMS calibrated reading from this site produced a date of $1203 \pm 34$ AD. We are inclined to disregard the latter reading, as it is far out of line with the other four readings from this site. This leaves us with ${ }^{14} \mathrm{C}$ dates that place the tested samples from Laguna de los Cóndores beginning around the late fifteenth century, which is around the time when it is thought the Incas entered the Chachapoyas area, until a few decades after the European invasion and the first entry of Spaniards into the Chachapoyas region, in 1535.

The two additional AMS dates obtained on khipu samples also dated between late pre-
Hispanic and early Colonial times. One sample (UR35/AS70), from a khipu in the Museo Chileno de Arte Precolombino, in Santiago de Chile, produced a non-calibrated AMS reading of $365 \pm 29$ BP (AA-49921), or calibrated age $1559 \pm 79$ AD. This sample was recovered from the site of Playa Miller \#6, near Arica, Chile. A khipu sample (without provenance) in Emory University's Carlos Museum a yielded non-calibrated AMS reading of $335 \pm 36 \mathrm{BP}(\mathrm{AA}-64905)$, or calibrated age $1571 \pm 81 \mathrm{AD}$ with $2 \sigma$ probability. Therefore, the radiocarbon dates from seven khipus from the far northern highlands of Peru to the north coast of Chile yielded dates from the period between late prehispanic to early Colonial times.

Three samples (41.2/7678, 41.2/7679, and 41.2/7681) from the Museum of Natural

Table 1. Radiocarbon chronology of Andean khipus.

\begin{tabular}{|c|c|c|c|c|c|c|}
\hline Lab ID & Sample ID & $\begin{array}{l}\delta^{13} \mathrm{C} \\
(\% 0)\end{array}$ & $\begin{array}{c}{ }^{14} \mathrm{C} \text { age } \\
\text { (years BP) }\end{array}$ & \pm & Calibrate & e (AD) \\
\hline AA-40080 & CMA.373.LC.2.002 & -26.0 & 414 & 35 & $1455-1505$ (0.679); 1588-1617 (0.321) & $1448-1521(0.556) ; 1536-1626(0.444)$ \\
\hline AA-40081 & CMA.419.LC1.048 & -21.9 & 403 & 35 & $1457-1509$ (0.579); 1580-1620 (0.421) & $1453-1626$ \\
\hline AA-40082 & CMA.628.LC1257B & -11.3 & 419 & 36 & $1453-1504(0.703) ; 1590-1616(0.297)$ & $1446-1626$ \\
\hline AA-40083 & CMA.847.LC1.476 & -24.5 & 834 & 35 & $1223-1269$ & $1188-1282$ \\
\hline AA-40084 & CMA.479.LC1.108 & -22.5 & 379 & 34 & $1487-1514(0.248) ; 1543-1624(0.752)$ & $1463-1630$ \\
\hline AA-46921 & MCHAP 780 & -12.1 & 365 & 29 & $1501-1594(0.858) ; 1613-1626(0.142)$ & $1480-1638$ \\
\hline AA-64905 & Carlos2002.1.118 & -24.7 & 335 & 36 & $1509-1580(0.771) ; 1620-1641(0.229)$ & $1489-1652$ \\
\hline UGAMS-4274 & $32-70-30 / F 851$ & -23.0 & 337 & 17 & $1511-1571(0.762) ; 1622-1636(0.238)$ & $1505-1588(0.768) ; 1617-1642(0.232)$ \\
\hline UGAMS-4275 & $41-70-30 / 3110$ & -22.6 & 355 & 17 & $1508-1583$ (0.906); 1619-1626 (0.094) & $1499-1598(0.831) ; 1610-1636(0.169)$ \\
\hline UGAMS-4276 & $42-28-30 / 4352$ & -21.4 & 377 & 23 & $1496-1512$ (0.189); 1546-1623 (0.811) & $1477-1630$ \\
\hline UGAMS-4277 & $32-30-30 / 54$ & -23.3 & 376 & 18 & $1498-1513$ (0.175); 1545-1623 (0.825) & $1484-1628$ \\
\hline UGAMS-4278 & $32-30-30 / 53 \mathrm{~A}$ & -21.1 & 377 & 17 & $1496-1512(0.204) ; 1548-1622(0.796)$ & $1481-1626$ \\
\hline UGAMS-4279 & $32-30-30 / 53 \mathrm{~B}$ & -22.8 & 313 & 17 & $1518-1538$ (0.314); 1625-1647 (0.686) & $1510-1576(0.462) ; 1621-1651(0.538)$ \\
\hline UGAMS-4280 & $41-52-30 / 2938$ & -22.3 & 368 & 17 & $1501-1515$ (0.171); 1541-1624 (0.829) & $1494-1631$ \\
\hline UGAMS-4571 & 42523 & -23.1 & 341 & 14 & $1511-1571$ (0.789); 1622-1634 (0.211) & $1506-1588(0.795) ; 1617-1640(0.205)$ \\
\hline UGAMS-4572 & 47095 & -23.1 & 351 & 22 & $1509-1579(0.888) ; 1620-1628(0.112)$ & $1498-1600(0.803) ; 1608-1640(0.197)$ \\
\hline UGAMS-4573 & $16635 / 3^{*}$ & -22.3 & 343 & 17 & $1511-1573(0.822) ; 1621-1633(0.178)$ & 1503-1591 (0.799); 1615-1641 (0.201) \\
\hline UGAMS-4574 & 63038 & -24.0 & 333 & 23 & $1511-1572$ (0.709); 1622-1640 (0.291) & $1503-1592$ (0.733); 1615-1647 (0.267) \\
\hline UGAMS-4575 & 42590 & -24.1 & 312 & 23 & $1514-1543(0.404) ; 1624-1649(0.596)$ & $1507-1586(0.526) ; 1618-1657(0.474)$ \\
\hline UGAMS-4576 & 42553 & -24.4 & 348 & 22 & $1510-1577$ (0.871); 1621-1630 (0.129) & $1499-1598$ (0.797); 1610-1641 (0.203) \\
\hline UGAMS-4577 & $16635 / 2^{* *}$ & -24.2 & 300 & 16 & $1631-1651$ & $1512-1548(0.150) ; 1622-1663(0.850)$ \\
\hline UGAMS-4578 & 16135 & -22.9 & 327 & 22 & $1512-1548(0.557) ; 1622-1643(0.365)$ & $1505-1589(0.686) ; 1617-1648(0.314)$ \\
\hline UGAMS-4579 & 47070 & -23.6 & 326 & 16 & $1513-1545(0.570) ; 1623-1643(0.430)$ & $1509-1582(0.646) ; 1620-1646(0.354)$ \\
\hline UGAMS-4580 & 42593 & -23.1 & 597 & 18 & $1395-1412$ & $1325-1341(0.093) ; 1390-1423(0.907)$ \\
\hline UGAMS-11798 & UR 87 & -22.1 & 353 & 15 & $1480-1521(0.569) ; 1591-1620(0.413)$ & $1468-1524(0.487) ; 1558-1631(0.513)$ \\
\hline UGAMS-11799 & UR 89 & -24.4 & 316 & 14 & $1522-1574(0.826) ; 1627-1638(0.174)$ & $1514-1600(0.790) ; 1617-1643(0.210)$ \\
\hline UGAMS-11800 & UR91 & -21.6 & 321 & 21 & $1520-1596$ (0.810); 1619-1635 (0.190) & $1490-1602(0.793) ; 1612-1643(0.207)$ \\
\hline UGAMS-11801 & UR92 & -22.8 & 364 & 15 & $1471-1513$ (0.688); 1600-1617 (0.312) & $1455-1522(0.633) ; 1574-1625(0.367)$ \\
\hline Beta-270947 & $41.2 / 6715$ & -22.4 & 380 & 40 & $1483-1514(0.273) ; 1542-1624(0.727)$ & $1460-1632$ \\
\hline Beta-270948 & $41.2 / 7678 \mathrm{a}$ & -22.1 & 1180 & 40 & $889-978$ & $780-791$ (0.021); 806-992 (0.979) \\
\hline Beta-270949 & $41.2 / 7678 b$ & -22.8 & 1140 & 40 & 896-923 (0.327); 940-993 (0.673) & $882-1024$ \\
\hline Beta-270950 & $41.2 / 7679$ & -22.5 & 1210 & 40 & 783-788 (0.040); 814-843 (0.197); & $777-981$ \\
\hline Beta-270951 & $41.2 / 7681$ & -23.3 & 1180 & 40 & $889-978$ & 780-791 (0.021); 806-992 (0.979) \\
\hline
\end{tabular}

ID, identification number; MCHAP, Museo de Arte Prcolombino. *Khipu on wooden bar w/3 male figures; ${ }^{* *}$ khipu on wooden bar w/2 monkey figures. 
History in New York of reputed Middle Horizon origin were recently dated by AMS. The samples produced radiocarbon ages between 1140 and 1210 years before 1950. After calibration to calendar age, these samples dated between 777 and $1024 \mathrm{AD}$, which is generally within the range assigned to the Middle Horizon period (600-1000 AD). The dates obtained for these samples have confirmed that cord keeping technology in the Andes began at least 1200 years ago with the thread-wrapped, Wari khipus of the Middle Horizon.

Twelve of seventeen samples from the Peabody museum at Harvard University and from the Berlin Museum für Volkerkunde tested by the University of Georgia AMS facility dated to the Spanish colonial period. Dates obtained for the remaining nine khipus (including four samples from the Museo Temple-Radicati, Lima, Peru) could be either before or after the beginning of European colonisation. The imprecision of the calibrations on these samples do not allow us to state more definite conclusions. We have attempted to compare the different samples having the same radiocarbon age but with different degrees of precision in their range of dates (Figure 3). The less precise measurement is \pm 40 years associated with a calibrated date with a range of 172 years - from 1460 till 1632 $\mathrm{AD}$ for $2 \sigma$ of standard deviation. The measurement with the error \pm 34 years shows about the same range, from 1463 till 1630. The most precise measurement, with the error \pm 17 years, slightly improves the calibrated age precision and makes the age interval almost 30 years narrower, from 1481 till $1626 \mathrm{AD}$. Thus, as it is shown in this example, the imprecise shape of the calibration curve does not allow us to measure precisely the chronological difference between late Inca and early colonial khipus.

The oldest Inca khipu dated by the radiocarbon technique, from The Museum of Natural History, New York, yielded a date of $1210 \pm 40$ (Beta-270950) years BP and a calendar age in the range of 777-981 AD (Figure 4). We have also analysed the relation between the precision of this measurement and the range of the calibrated ages for Middle Horizon khipus. One of the samples was analysed twice (an original sample and a duplicate). We have calculated the weighted average value for this khipu and the standard deviation (Figure 5) as follows:

$$
\mathrm{A}_{\mathrm{wAV}}=\frac{\mathrm{A}_{1} / \sigma_{1}{ }^{2}+\mathrm{A}_{2} / \sigma_{2}{ }^{2}}{1 / \sigma_{1}{ }^{2}+1 / \sigma_{2}{ }^{2}} ; \sigma_{\mathrm{wAv}}\left[\mathrm{V}\left(1 / \sigma_{1}{ }^{2}+1 \sigma_{2}^{2}\right)\right]^{-1}
$$

where: $A_{\text {wav }}$ and wav are weighted average for the age and standard deviation correspondently; $A_{1}$ and $A_{2}$ radiocarbon age for the first and second measurements; $\sigma_{1}$ and $\sigma_{2}$ standard deviation for the first and second measure-
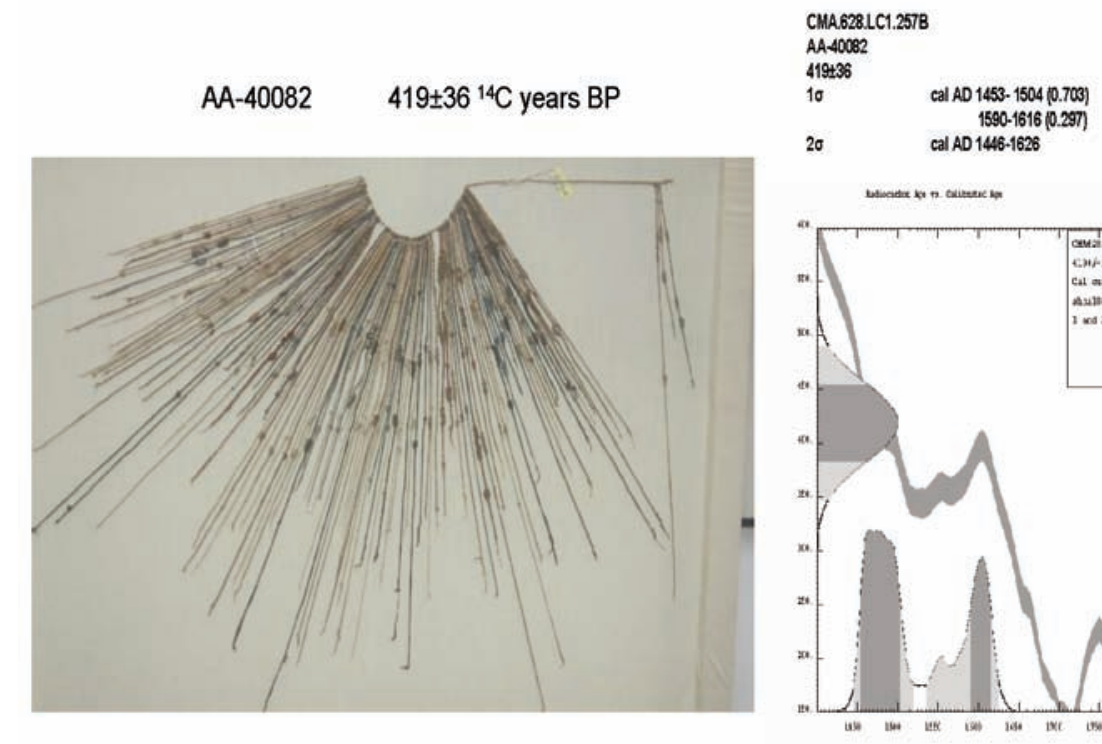

Figure 2. Decimal khipu (khipu CMA.628.LC1.257B=UR2) from Peru (Centro Maliqui) more likely belongs to Inca period. The graph on the right shows the relative calibration results.

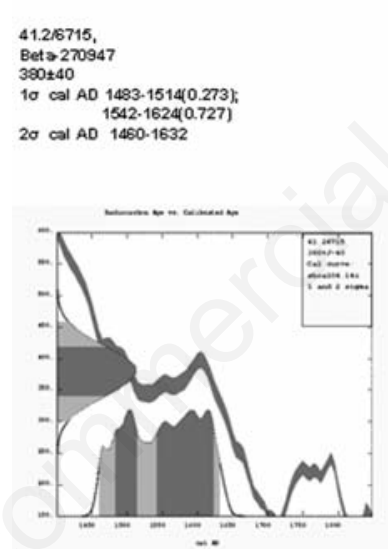

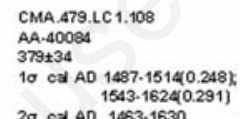

$2 \sigma$ ed $A D$ 1543-1624(0.291) 1403.1630

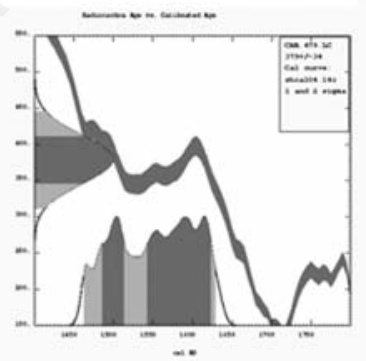

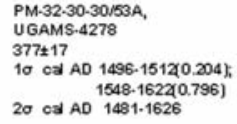

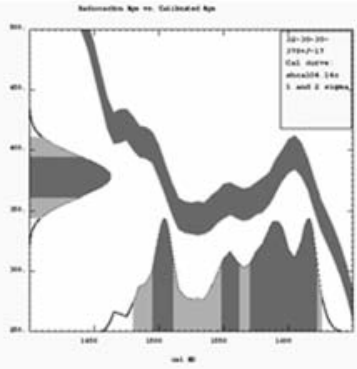

Figure 3. The effect of measurement precision on calibration results.

\section{Beta-270950 $\quad 1210 \pm 40{ }^{14} \mathrm{C}$ years $\mathrm{BP}$}
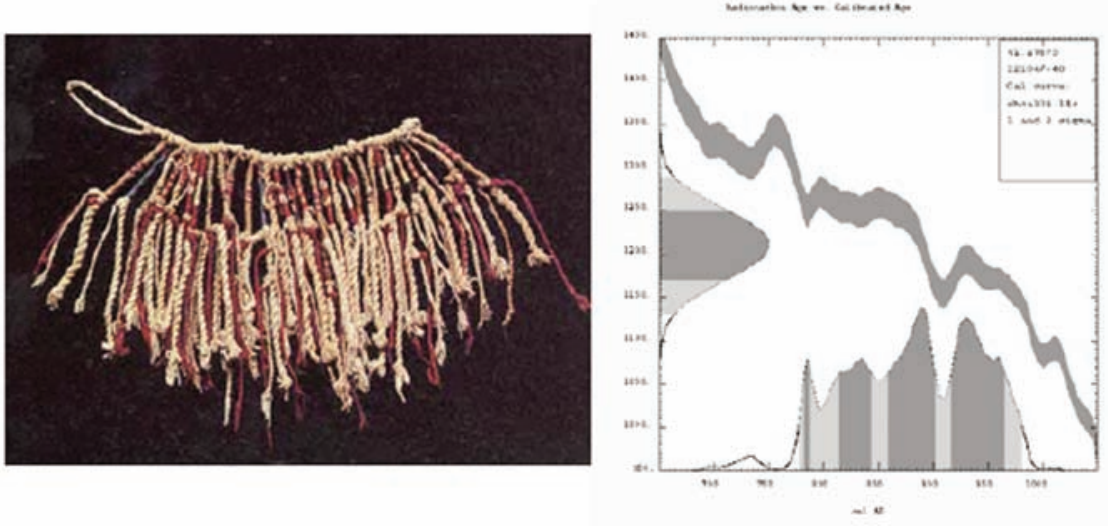

Figure 4. The oldest radiocarbon dated khibu (khipu 41.2/7679 from the American Museum of Natural History, New York). The graph on the right shows the relative calibration results. 
41.27 $678 \mathrm{a}$

Beta-270948 $1180 \pm 40$

$1 \sigma$ cal AD $889-978$

$2 \sigma$ cal AD 780-791(0.021); 806-992(0.979)

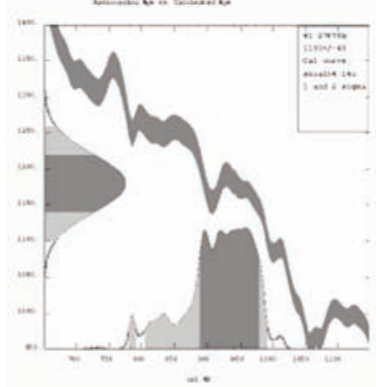

41.277678b

Beta-270949 $1140 \pm 40$

$1 \sigma$ cal AD 896-923(0.323);

940-993(0.673) 20 cal AD $882-1024$

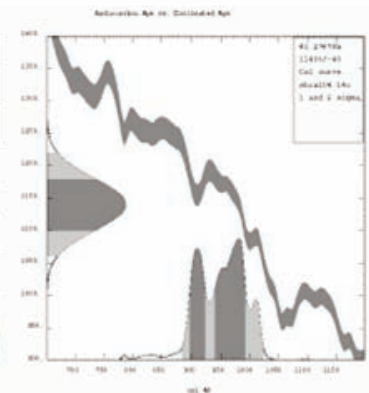

41.27678, $1160 \pm 28$

10 cal AD 897-921(0.376); $942-982(0.624)$

$2 \sigma$ cal AD $884-993$

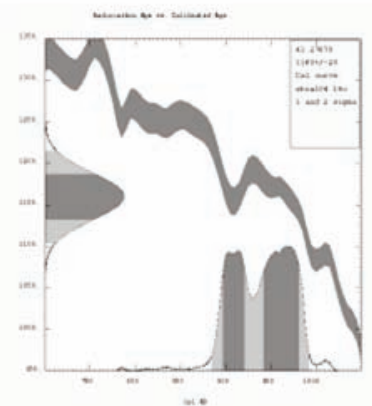

Figure 5. The radiocarbon age calibration of the oldest khipu.

ments. All three values were then calibrated in calendar ages. When the standard deviation was \pm 40 years, the calendar range exceeded 140 years, whereas in the case of the standard deviation of \pm 28 , the calendar range was less than 110 years, for $95 \%$ probability.

Radiocarbon dating can help in the general determination of the age of samples in the chronological range discussed in this article. However, the method does not allow us to obtain single year dates, thus, the measurements must be subjected to statistical interpretive processes. Moreover, the calibration curve also has some standard variation, and in some ranges the concentration of radiocarbon in the atmosphere has changed in ways so that the single radiocarbon date crosses the curve a few times, making the calibrated range much wider than the statistical error of the measurement. As a consequence, the dates obtained for the Inca samples fall within a range, the width of which, because of the imprecision in the calibration curve, is unfortunately much wider than is desirable for precise dating.

\section{Conclusions}

The radiocarbon ages for the khipus have confirmed the Middle Horizon origin of cordkeeping in the Andes. The oldest sample was made between the end of the $8^{\text {th }}$ and the $10^{\text {th }}$ century. Most of the dated Inca samples fall in the range between 1446-1663 AD. However, each sample has such a wide interval in its calibrated ages that it is difficult to identify precisely to which period each belongs. Even high precision measurements, having standard deviation better than \pm 20 years, do not allow us to attribute samples with confidence to the Inca or the Colonial period. This problem arises from the lack of a precise calibration for this interval of ages. This situation calls for the development of a better calibration curve for South America. Only one sample, a khipu from the Museum für Völkerkunde (VA 42593), which dated to 1390-1423 AD, definitely confirms that the tradition of knotted, decimalbased Inca-style khipus began by the beginning of the Late Horizon.

\section{References}

Ascher M, Ascher R, 1997. Code of the Quipu. Dover Publ., New York.

Cherkinsky A, Culp RA, Dvoracek DK, Noakes JE, 2010. Status of AMS facility at CAIS, University of Georgia. Nuclear Instrum Meth B 268:867-70.

Conklin WJ, 1982. The information system of the Middle Horizon quipus. In: A.F. Aveni and G. Urton (eds.) Ethnoastronomy and archaeoastronomy in the American tropics. New York Academy of Sciences, New York, pp 261-81.

Damon PE, Donahue DJ, Gore BH, Hatheway AL, Jull AJT, Linick TW, Sercel PJ, Toolin LG, Bronk CR, Hall ET, Hedges REM, Housley R, Law IA, Perry C, Bonani G, Trumbore S, Woelfli W, Ambers JC, Bowman SGE, Leese MN, Tite MS, 1989. Radiocarbon dating of the Shroud of Turin. Nature 337:611-5.

Pärssinen M, Kiviharju J, 2004. [Textos Andinos: corpus de Textos khipu incaicos y coloniales, 1]. [Book in Spanish]. Instituto Iberoamericano de Finlandia and Universidad Complutense de Madrid ed., Madrid.

Pereyra H, 1997. [Los quipus con cuerdas entorchadas]. In: R. Varón Gabai, J. Flores Espinoza (eds.) [Arqueología, antro pología e historia en los Andes: Homenaje a María Rostworowski]. [Book in Spanish]. Instituto de Estudios Peruanos, Lima, pp 187-98.

Reimer PJ, Baillie MGL, Bard E, Bayliss A, Beck JW, Blackwell PG, Bronk Ramsey C, Buck CE, Burr GS, Edwards RL, Friedrich M, Grootes PM, Guilderson TP, Hajdas I, Heaton TJ, Hogg AG, Hughen KA, Kaiser KF, Kromer B, McCormac FG, Manning SW, Reimer RW, Richards DA, Southon JR, Talamo S, Turney CSM, van der Plicht J, Weyhenmeyer CE, 2009. IntCal09 and Marine09 radiocarbon age calibration curves, 0-50,000 years cal BP. Radiocarbon 51:1111-50.

Urton G, 2003. Signs of the Inka khipu: binary coding in the Andean knotted-string records. University of Texas Press ed., Austin.

Urton G, 2008. The Inka khipu: knotted-cord record keeping in the Andes. In: $\mathrm{H}$. Silverman and W. Isbell (eds.) Handbook of South American Archaeology. Springer, New York, pp 831-44.

Vogel JS, Southon JR, Nelson DE, 1987. Catalyst and binder effects in the use of filamentous graphite for AMS. Nuclear Instrum Meth B 29:50-6. 